\title{
El contexto de la salud malaya: sistema humoral, medicina tradicional, reproducción y ritos de paso
}

\author{
Malay health in context: \\ humoral system, traditional medicine, reproduction \\ and rites de passage
}

\author{
Hugo Valenzuela García \\ Departamento de Antropología \\ Universidad Autónoma Metropolitana. \\ Unidad Iztapalapa. México
}

\section{RESUMEN}

El autor presenta algunos de los fundamentos de la cultura malaya en relación con la salud y la enfermedad en el ámbito rural. La cosmología malaya se basa en un corpus sincrético integrado por creencias animistas e Islam. El contenido cognitivo y simbólico de este corpus heterogéneo resulta particularmente ejemplar para revelar tanto aspectos generales de la cultura malaya (cosmología, estructura social, relaciones de género, hechicería) como aspectos singulares relacionados con la salud y la enfermedad (comprensión del cuerpo, reproducción, enfermedad). La descripción etnográfica de este sistema permite un doble ejercicio metodológico: abordar el contexto social y cultural en el que se concibe localmente la enfermedad entre los malayos y dilucidar vínculos de comparación con otras sociedades musulmanas en el contexto del sistema biomédico contemporáneo.

Palabras clave: Etnografía, Cosmología, Salud, Medicina tradicional, Ritos de paso, Malayos rurales.

\section{SUMMARY}

The author introduces some of the foundations of Malay culture with respect to health and disease in a rural context. Malay cosmology is grounded in a syncretism of animistic beliefs with Islam. The cognitive and symbolic contents of this cosmology reveals general aspects of Malay culture (cosmology, social structure, gender relationships, witchcraft) as well as specific aspects of the same as they pertain to health and illness (understanding of the body, reproduction, disease). Ethnography is predicated on a twofold methodological exercise: identifying the social and cultural context in which dis- 
ease is understood locally and eliciting elements for comparison with other Muslim social formations in the context of contemporary biomedical systems.

Key words: Ethnography, Cosmology, Health, Traditional medicine, Rites de passage, Rural Malays.

\section{INTRODUCCIÓN}

Las sociedades del Sudeste Asiático presentan una inmensa y compleja riqueza etnográfica. Pero a diferencia de otras regiones del mundo, este subcontinente en general, y Malaysia en particular, han recibido escasa atención antropológica en el ámbito hispanohablante. Este vacío etnográfico es producto de la combinación de diversos factores: primero, la lejanía geográfica, histórica y geopolítica entre España y esta región, a excepción de Filipinas. Segundo, una historiografía deficiente que ha equiparado el Sudeste Asiático con una extensión cultural de China, obviando así la especificidad sociocultural interna de la región. Finalmente, la compleja tarea de aprender lenguas tan alejadas de la tradición indoeuropea (Osborne 2000).

La aducida complejidad de las tradiciones culturales de esta región obedece, en gran parte, a una profunda amalgama de influencias religiosas y culturales, un sustrato sincrético que impregna buena parte de las manifestaciones culturales, desde el arte a la medicina (Valenzuela 2006a; Winsted 1951). En concreto, la sucesiva influencia histórica de animismo, budismo, hinduismo o islam ha impregnado prácticas y creencias médicas no exentas de contradicciones, particularmente en regiones dominadas por religiones normativas y abrahámicas como el cristianismo (Filipinas) o el islam (Indonesia, Malaysia o Brunei).

El contexto de las prácticas y creencias médicas resulta particularmente apropiado para analizar el sincretismo de las sociedades del sudeste asiático, dada la influencia simultánea de influjos animistas, religiosos y biomédicos. Un ejemplo paradigmático de la complejidad aquí señalada lo presenta la sociedad malaya, que tomamos aquí como estudio de caso y objeto de análisis etnográfico. Paradójicamente, el caso malayo, por virtud de la gran influencia musulmana subyacente, presenta un contrapunto comparativo a otras sociedades musulmanas crecientemente presentes en España.

El texto persigue por lo tanto dos objetivos: primero, ofrecer una perspectiva etnográfica sobre una región relativamente desconocida en la que los aspectos relacionados con la cosmovisión, las creencias y las prácticas en torno a la salud y la enfermedad resultan particularmente ricos y sincréticos. En este sentido se describirán los fundamentos epistemológicos que subyacen a la cosmovisión local, a la interpretación de la enfermedad 
y a la práctica médica tradicional. En segundo lugar, salvando los problemas metodológicos inherentes a la comparación transcultural, se subrayará la relevancia del sustrato musulmán de la práctica médica malaya, dado su potencial comparativo con las prácticas y creencias propias de otros colectivos musulmanes inmigrados al territorio español.

Este artículo se basa en un trabajo de campo antropológico de dieciséis meses de duración realizado entre los años 2003 y 2005 en la pequeña isla pesquera de Pulau Tuba, en el archipiélago de Langkawi, al noroeste de la Península de Malaysia (Valenzuela 2006b). El trabajo de campo tuvo un enfoque clásico en el que se priorizó la estancia prolongada in situ, la observación participante y el aprendizaje de la lengua vernácula. La asimilación de los rudimentos fundamentales de la cultura malaya fue posible gracias a la adopción del investigador en el seno de una familia de pescadores de la isla. Esta circunstancia no sólo me invistió de una serie de obligaciones y derechos por virtud de mi posición en la estructura de parentesco, sino que me permitió también tener acceso a espacios y eventos privilegiados, difícilmente accesibles desde otro rol o circunstancia: ritos de paso, exorcismos, ceremonias locales, realidad doméstica de la población, curas médicas tradicionales, actos furtivos (como peleas de gallos o prácticas mágicas), etc.

Paralelamente a la observación participante, se aplicaron numerosas y variadas técnicas cualitativas y cuantitativas: cuestionarios, taxonomías, redes sociales, microanálisis de la productividad pesquera, entrevistas abiertas y semiestructuradas, etc. Destaca, en ausencia de datos demográficos oficiales, la administración de un censo y un amplio cuestionario a la totalidad de la población insular: 1.349 individuos distribuidos en 329 unidades domésticas.

El $99 \%$ de la población es malaya y musulmana, razón por la cual la isla también se conoce popularmente como Pulau Islam. La principal actividad económica es la pesca tradicional o de bajura y la principal explotación comercial es la captura de gamba, que ocupa al $14.8 \%$ de los varones adultos. El resto de las ocupaciones laborales responden a actividades rurales o escasamente especializadas. La población presenta elevadas tasas de mortalidad y natalidad, un notable grado de pobreza y, comparativamente, un nivel socioeconómico y de educación formal muy por debajo de la media nacional. Debido a la escasez de oportunidades laborales insulares, la isla registra una elevadísima tasa migratoria (del $27 \%$ ), siendo las ciudades peninsulares y urbanas el principal destino. 
EL CRISOL MULTICULTURAL Y LA INFLUENCIA ISLÁMICA

Malaysia presenta un ejemplo paradigmático de sociedad multicultural debido a la extraordinaria diversidad étnica, religiosa, fenotípica y lingüística de su población (Andaya y Andaya 1982). Étnicamente hallamos malayos $(50,2 \%)$, chinos $(24,5 \%)$, indios $(7,2 \%)$, población no malasia $(5,9 \%)$ y una heterogénea minoría agrupada bajo el epíteto de otros (1,2\%). Los malayos y los numerosos grupos indígenas peninsulares constituyen la población bumiputera (o "hijos de la tierra"), que goza de privilegios políticos exclusivos. Aunque oficialmente existen diecinueve grupos orang asli con rasgos dialectales y pautas culturales diferenciadas, administrativamente se agrupan en tan sólo tres categorías: los denominados, no con gran fortuna, Negritos (2.700 en 1994), emplazados en la zona central y el norte peninsular. Los Senoi, que habitan la zona central peninsular y agrupan a Temiar (15.122) y Semai (26.076). Y por último, los denominados malayos aborígenes o protomalayos, compuestos por Temuan (16.015) y Jakun (16.637). En la zona insular de Sarawak, aparte de sino-malasios, indio-malasios e inmigrantes filipinos o indonesios, hallamos muy diversos grupos indígenas: Iban, Dayak, Bidayuh, Melanau, Kayan, Kenyah, Kajang, Lun Bawang, Kelabit, Bisaya, Tagal, Kedayan, Penan, Punan, etc. En Sabah hallamos Kadazan, Rungis, Dusun, Sama-Bajau, Murut, etc. (Nicholas 1990; Dentan et al. 1997).

El resto de poblaciones étnicas presenta asimismo una notable diversidad interna. Entre el colectivo chino hay hablantes de hakka, teochiew, bokkien, cantonés, hailam y mandarín y, aunque el tamil es la lengua principal del contingente indio, existe profusión de dialectos. Las manifestaciones religiosas presentan también gran heterogeneidad: el Islam es practicado por la mitad de la población, el $25 \%$ practica alguna de las diversas religiones tradicionales chinas, el $7 \%$ hinduismo, el $6 \%$ budismo, el $6 \%$ cristianismo (católicos, metodistas, protestantes, etc.) y la minoría restante sigue creencias diversas: animismo, taoísmo, confucionismo...

El grupo étnico más numeroso y políticamente dominante es el malayo (50.25\%, año 2000), que se agrupa mayoritariamente en zonas rurales. En el artículo 160(2) de la Constitución Federal hallamos: "malayo es todo individuo que profesa la religión musulmana, habla habitualmente la lengua malaya y se adhiere a sus costumbres". Sin embargo, aunque la lengua y el Islam han contribuido decisivamente a fortalecer la identidad malaya (Omar 1998; Nagata 1976, 1984), el Islam malayo presenta un elevado grado de heterogeneidad y sincretismo, derivado del pasado animista, de la influencia religiosa hinduista y budista, y del sistema costumbrista tradicional (adat). 
El Islam es una religión compleja, diversa y militantemente evangelista que divide a la humanidad entre Dar ol Islam (mundo de sumisión al Islam) y Dar ol Harb (mundo de guerra contra Dios), a pesar de que judíos y cristianos (referidas como las gentes del Libro) gozan de una posición especial en el credo islámico. Islam significa sumisión y el Corán insiste en que Alá posee un control absoluto sobre el mundo y sus criaturas. En Malaysia, masuk Islam (literalmente, "entrar en el Islam") es sinónimo de masuk melayu ("devenir malayo") o, en otros términos, el malayo nace musulmán, bajo una religión que no distingue entre vida secular y religiosa, dado que los principios islámicos controlan todos los asuntos humanos y mundanos (Nagata 1974). Sus preceptos vertebran cada uno de los actos y hábitos del individuo, su pensamiento y la mayor parte de sus fases vitales, incluso tras la muerte (akhirat). Como apunta Muzaffar,

El Islam toca la vida del malayo en mil puntos. A través de las oraciones entra en la vida rutinaria de la persona. Mediante el ayuno entra en el ciclo anual. Se relaciona con las reglas asociadas al nacimiento y la muerte, el matrimonio y la herencia. Sus normas [...] condicionan el tipo de comida que uno come y el tipo de ropa que viste. Las normas de etiqueta de la comunicación social siempre están influenciadas por los preceptos islámicos [...] pues las normas del comportamiento derivadas en cuestión se derivan fundamentalmente de rituales y prácticas que están dictadas casi exclusivamente por la religión (en Said 1993: 29).

Desde la introducción del Islam en el siglo XIV (por influencia de comerciantes indios y no árabes), la cultura malaya fue indeleblemente transformada. Hoy el Islam malayo es más que una religión, es ad-Din, "una forma total de vida" (Geertz 1971), que inspira tanto las relaciones de género, como las cuestiones políticas o la cohesión comunitaria (ummab). A partir de finales de los años 70, el Islam malayo experimenta un recrudecimiento ortodoxo, como ocurrió en muchos países islámicos a partir de la Revolución de Irán (1979). En Malaysia este movimiento ortodoxo estuvo liderado por un grupo diverso compuesto en gran parte por jóvenes malayos urbanos, que recibió el nombre de dakwah ("llamada", "invitación a la fe"). Este movimiento promovía el regreso a la escrupulosidad de las escrituras, una indumentaria femenina más modesta, una segregación sexual más estricta, el rechazo de vestigios preislámicos (que toma la forma de cruzada contra el animismo y sus manifestaciones) y la oposición abierta a ciertos valores occidentales considerados decadentes y amorales.

Para el malayo Alá es el único Dios, omnipresente y todopoderoso, por debajo del cual se hallan los ángeles, los diablos, los seres humanos, los jin (o genios), los animales y las plantas. La fe en Alá es indiscutible, luego cuestionar el predicamento del Corán (que a menudo se toma como la pa- 
labra literal de Alá) es herejía. De acuerdo con el Islam todas las actividades de un musulmán se consideran actos religiosos (ibadab), divididos en acciones dirigidas a Dios y acciones dirigidas a los congéneres humanos (fardhu kifayah). Las primeras componen los cinco pilares mencionados y las segundas se consideran mu' alamat ("prestaciones sociales") en la literatura islámica. El Islam y sus escrituras agrupan un heterogéneo corpus de doctrinas sociales, económicas y morales, tales como la prohibición de la usura o consumo de alcohol, el tabú sobre la ingestión del cerdo o carne animal que no haya sido sacrificada siguiendo los ritos musulmanes ( alal $^{1}$, la prohibición de tocar a ciertos animales (cerdos y perros), segregación sexual, etc. Estos serían, sintéticamente, los principios fundamentales del Islam. En el caso malayo estos principios se fusionan con vestigios animistas e hindúes, dando lugar a un sincretismo particularmente evidente en el sistema humoral, fundamento esencial de la comprensión local de la salud y la enfermedad.

\section{EL SISTEMA HUMORAL}

Al principio del trabajo de campo la adaptación al bochornoso clima tropical malayo fue lenta: estaba constantemente empapado de sudor y, para evitar la deshidratación, necesitaba ingerir un gran volumen de agua durante el día. Wahid, un anciano aldeano que me acompañó durante mi trabajo de campo, diagnosticó que mi cuerpo estaba demasiado sejuk (frío) y me recomendó tomar café caliente y aplicarme minyak angin (un ungüento aceitoso con mentol). En otra ocasión, en plena estación de las lluvias, fui aquejado por las fiebres propias de una gripe tropical. Mi madre adoptiva me recomendó: (sic) kalau demam jangan makan buab-buah, buab sejuk, lagi baik makan panas...kopi panas boleh minum, tapi teh tak boleh...mandi sejuk tak boleb juga... ("Si tienes fiebre no debes comer fruta, la fruta es fría, mejor que comas caliente... puedes tomar café caliente pero no té... evita también las duchas frías"). Estos intrigantes consejos, que se manifestaron sólo durante estados de debilidad o enfermedad puntual, apuntaban a un corpus simbólico subyacente: el sistema humoral.

El pasado de Malaysia estuvo marcado por un activo comercio ultramarino que dio lugar a una profunda influencia de ideas pertenecientes al sis-

\footnotetext{
${ }^{1}$ Aunque existen diversas interpretaciones, halal responde a una práctica y filosofía relacionada con el alimento: un alimento halal no debe tener contacto con sustancias prohibidas. En el caso de la carne, debe proceder de un animal sacrificado sobre el cual se menciona el nombre de Alá y se desangra según unas pautas concretas.
} 
tema humoral chino, indio-ayurvédico y, tardíamente, árabe medieval (legado, a su vez, de la medicina europea hasta el siglo XVII en la que destacaron especialmente Galeno e Hipócrates). Debido a que la cosmología aborigen original ya barajaba la dicotomía frío-caliente, gran parte de esas ideas fueron bien asimiladas y el modelo humoral malayo devino un producto sincrético de la influencia ancestral (con nociones propias como la pérdida del alma o el ataque espiritual), los diversos sistemas humorales y las creencias islámicas.

Este sistema se inscribe dentro de una particular concepción de la humanidad, las personas y las sustancias y, como han mostrado Good y Del Vecchio (1992), su expansión transcultural y la capacidad de adaptarse al contexto local es muy notable. Este sistema, que se remonta al modelo árabe-medieval, entiende que la mujer es la parte imperfecta de la humanidad. La naturaleza femenina es fría, porque se creía que la mujer se engendraba a partir de los residuos del esperma que su progenitor depositaba en la parte izquierda del útero de su madre — la zona más fría. Por el contrario, el varón y especialmente su esperma, se definen como connaturalmente calientes. Puesto que el cerebro de la mujer es más frío, se cree que ésta adolece del coraje, de la valentía y de la fuerza moral propios del hombre. En el pasado, la mujer, particularmente en momentos de enfermedad, debía evitar el contacto prolongado con fuentes frías. Beber excesiva agua, bañarse en el mar, aposentarse en superficies frescas o ingerir alimentos gélidos podía empeorar, según se creía, su estado de salud. Los alimentos fríos, a evitar en lo posible, se relacionaban con el gusto insípido o ácido de ciertas verduras y frutas.

Al varón, contrariamente, con el fin de potenciar su salud física y su semilla (esperma), le aplicaban cataplasmas calientes y le proporcionaban una dieta rica en alimentos calientes: comidas dulces, saladas, amargas, proteicas y grasas (aceite, carnes, café, etc.). El esperma se consideraba una substancia particularmente caliente y, por lo tanto, el varón debía dosificar su actividad sexual para evitar un excesivo enfriamiento y un desgaste energético perjudicial. Tener una sexualidad excesivamente activa implicaba secar la semilla y comportaba el riesgo de perder la lucidez, enfermar o incluso morir prematuramente, pues se creía que el esperma se almacenaba en el cerebro y era la fuente de la racionalidad (akal malayo) que el varón transmitía al feto. La deposición de la semilla era un momento peligroso en el proceso de procreación pues, al entrar en contacto con el frío femenino, podía malograrse. El varón también debía evitar las relaciones sexuales con ancianas o mujeres que acababan de alumbrar, pues se creía que éstas, en estado particularmente frío, podían succionar su calor y causarle la enfermedad. 
Para la mujer, naturalmente, el periodo más peligroso era el parto, pues la pérdida de sangre (elemento caliente por antonomasia) comportaba un enfriamiento excesivo. Durante el delicado periodo de posparto la mujer recuperaba progresivamente su calor interno, siempre que cumpliese una serie de tabúes destinados a evitar la enfermedad. Con la edad, tanto el hombre como la mujer perdían paulatinamente su calor corporal, llegando a la muerte en un estado de total frialdad. Una vida larga y saludable exigía el equilibrio en todas las actividades humanas: moderación en la alimentación, en la actividad física, sexual, intelectual, etc. La dieta, salvo en las zonas temperadas, debía evitar los alimentos fríos.

El sistema greco-musulmán y el malayo, a pesar de sus similitudes, presentan algunas diferencias. En particular, en el caso malayo se produce una inversión de las cualidades de las sustancias. En el sistema greco-musulmán el frío tiene una connotación negativa y el calor, positiva. En el malayo ocurre lo contrario: el frío se relaciona con la salud, la fertilidad y el coito, mientras que el calor se asocia a la enfermedad, la esterilidad, el aborto y la impotencia. El modelo árabe distingue entre cualidades activas (calor y frío) y pasivas (búmedo y seco), pero los malayos unen las últimas a las primeras (calor-seco y frío-búmedo) y su sistema no posee grados humorales.

El sistema humoral implica una serie de indicios y principios observables en el contexto de la salud, pero también en muchos otros ámbitos de la vida malaya rural (brujería, apuestas, comprensión del carácter del individuo, etc.). Por ejemplo, en el transcurso de una lucha de gallos furtiva, un anciano me dijo que las cifras de las apuestas no podían coincidir con el 3, el 7, el 11, el 15, etc. Me explicó que adjudicaban un número a cada uno de los elementos, de modo que el 1 coincidía con agua, el 2 con aire, el 3 con fuego y el 4 con tierra. Las apuestas tendían a evitar las cifras que cayesen en el elemento fuego (3, 7, 11, 15, etc.), el símbolo de lo caliente, una calidad generalmente asociada a los espíritus malignos, la enfermedad y la mala suerte.

De acuerdo con Laderman, "en Malaysia, la etiología de la mayoría de las enfermedades, y su tratamiento, encaja con el modelo humoral" (1991: 20). La salud se concibe como un estado equilibrado de sustancias y, en consecuencia, la enfermedad aparece cuando el sistema se desequilibra. El sistema humoral malayo parte de que toda la materia (inclusive la humana) se compone de cuatro elementos: tanab (tierra), air (agua), api (fuego) y angin (aire), cuyas cualidades implican diversos grados de frío o calor. El equilibrio de estos elementos es fundamental para garantizar la salud física y psicológica (espiritual), y su regulación suele depender de las características de los alimentos ingeridos, cuya composición regula la calidad y canti- 
dad de las sustancias corporales. Sin embargo, el equilibrio de las sustancias corporales también puede estar afectado por factores exógenos, como la temperatura ambiental o el ataque de un espíritu.

Además de los alimentos fríos, neutros y calientes, existen aquéllos denominados bisa, que a menudo se han confundido con los fríos, pues ambos se desaconsejan en caso de vulnerabilidad física o cuando se prescribe algún tipo de tabú alimenticio (pantang larang). Por lo general, bisa hace referencia a un tipo de sustancia que puede agravar el estado de salud de un individuo que ya se encuentre en un periodo de debilidad puntual. Se traduce genéricamente como veneno, pero también se asocia al efecto protervo de los espíritus malignos. Por ejemplo, cuando un espíritu del mar ataca a un pescador se dice que le transmite bisa. En Tuba, los alimentos considerados bisa son el marisco (gambas, cangrejos, moluscos diversos, etc.), algunos tipos específicos de pescado, la piel de aves y los alimentos de olor o aspecto desagradable. Las especies de peces que caen en la categoría bisa suelen compartir rasgos anómalos o inusuales: peces con grandes escamas, moteados, con aletas ponzoñosas, de colores rojizos o amarillentos. También consideran bisa a aquellas especies de fondo que se nutren de despojos o de organismos muertos y, dada la creencia malaya de que uno es lo que come, consideran que la ingestión de esos pescados acentúa la enfermedad. En realidad esta asociación no es arbitraria, ya que en muchos casos los alimentos catalogados como bisa poseen características que coinciden con la toxicidad observada en algunas carnes de pescado expuestas a condiciones y temperaturas específicas. A saber, a elevadas temperaturas la carne de algunas especies marinas puede ser potencialmente tóxica, ya sea como consecuencia de los elementos químicos que emplean como mecanismos de defensa ciertas especies tropicales o por la segregación de enzimas perniciosos para el organismo humano. Sobre una muestra de 54 especies de pescado clasificadas como bisa, un tercio presentaba características tóxicas o nocivas para la salud (Laderman 1983: 70).

A lo largo de los párrafos anteriores hemos hecho alusión a alimentos fríos, calientes y neutros, pero esas cualidades no responden a características térmicas. En ocasiones sugieren asociaciones sensitivas relacionadas con la textura, la humedad o la apariencia. Por ejemplo, el alcohol, la carne de cabra o el durian (una fruta cremosa y grasa) se consideran alimentos muy calientes; el café, la carne de vaca y búfalo, o la sandía, se consideran calientes; mientras que el té, la mayoría de las frutas y hortalizas y el agua se consideran fríos. Significativamente, el arroz y el pescado común (ikan kambong, una especie de scombridae muy abundante en las costas del Mar de Andamán) caen en la categoría de alimentos neutros, pues constituyen 
ingredientes fundamentales de la dieta cotidiana. Como puede apreciarse, los isleños no comparten un consenso claro sobre la clasificación de los alimentos, lo cual dificulta el establecimiento de taxonomías de sustancias en relación a los humores. A pesar de estas dificultades, es posible establecer una casuística mínima que, en algunos casos, pudiera coincidir con el pronóstico médico de nutricionistas y dietistas. Los alimentos calientes serían aquéllos que satisfacen rápidamente el apetito y producen sensación de calor y plenitud (carnes, grasas, alcoholes, especies picantes, alimentos amargos y salados...), luego posiblemente remiten a alimentos calóricos, proteicos y ricos en azúcares. Los alimentos fríos suelen coincidir con alimentos frescos, acuosos y jugosos, como verduras o frutas. Los alimentos neutros, como hemos visto, son aquéllos que no caen en ninguna de estas categorías y suelen tener un efecto neutral sobre la salud (arroz, algunos tipos de pescado, carne de pollo, etc.).

Además, el equilibrio humoral depende, tanto de las características del individuo, como de la influencia de factores exógenos cambiantes como la temperatura o el clima. Se cree, por ejemplo, que la brusca alteración de la temperatura ambiental (común en las zonas tropicales) incide negativamente en el reajuste de la temperatura corporal, desequilibrando el sistema humoral y dando lugar a catarros, fiebre, gripe o neumonías. Por esta razón, los pobladores evitaban exponerse a la lluvia cuando brillaba el sol, o ducharse inmediatamente después de realizar una actividad física o durante el atardecer y el alba, pues en esos momentos la influencia espiritual podría resultar particularmente nociva. Como veremos más adelante, el pensamiento mágico se asocia con las transiciones, las intersecciones, la fusión de esferas o los eventos anómalos e inusuales.

En conclusión, los mecanismos del sistema humoral se manifiestan, o se hacen evidentes, en momentos críticos en los que la salud del individuo se hace vulnerable. Esta vulnerabilidad puede estar causada por la particular situación del individuo (vejez, ciertos ritos de paso o transiciones biológicas, proceso de parto o posparto), por accidente o enfermedad (lesión, herida, gripe), puede ser inducida por la ingesta de ciertos alimentos (excesivamente fríos o calientes) o ser provocada por el ataque de un espíritu maligno (descrito a menudo como una fuente de calor extremo). Los ámbitos del ritual, la alimentación y la brujería resultan por lo tanto cruciales para efectuar un análisis de las bases culturales y simbólicas que subyacen a la comprensión e interpretación local de la enfermedad y la salud. Analicemos a continuación estos ámbitos del contexto de la enfermedad. 


\section{MEDICINA TRADICIONAL}

El pensamiento mágico malayo implica un corpus sincrético y heterogéneo compuesto por animismo ancestral impregnado de hinduismo, sufismo islámico e ideas procedentes del brahmanismo maharaya, sivaísmo, tantrismo y budismo. Por esa razón, la hechicería malaya inicialmente se describió como animismo infuso (Skeat 1900), culto de la vida (Cuisinier 1936) o panteísmo místico (Winstedt 1922) (citados en Endicott 1970: 28). Este sistema de creencias se fundamenta en la idea de un mundo invisible, espiritual (alam ghaib), que es la contrapartida, el reflejo o la simetría, del mundo visible o sociocultural (alam nyata). Lo anormal, inusual o excepcional es propio del mundo invisible, contrapartida de lo normal, usual y común hallado en el mundo visible. Por esa razón, el pensamiento popular malayo suele atribuir la influencia mágica a la anormalidad y a las patologías incomprensibles. Lo mágico, tal y como se observó durante el trabajo de campo, puede asociarse por lo tanto con una malformación congénita, con el fallecimiento por hemorragia interna de una mujer parturienta, con la parálisis súbita de un adolescente, con la depresión, con el retraso mental, con comportamientos desviados o agresivos, con la promiscuidad, o con un enamoramiento pasional.

La etiología de la medicina tradicional malaya (ubat tradisional) es "casi por completo mágica: su diagnosis es la adivinación, las causas de la enfermedad son fuerzas sobrenaturales y sus curas usan métodos mágicos con los cuales esas fuerzas pueden ser tratadas" (Endicott 1970: 26). El sanador tradicional recibe el nombre de bomob y su función es, en esencia, restablecer el equilibrio cosmológico, mediante la reordenación de las sustancias que componen el cuerpo (humores) y de las esencias que componen el mundo social y natural. Por lo tanto, el bomoh es tanto un médico tradicional (que diagnostica y trata la enfermedad reequilibrando los humores) como un hechicero o mago (cuyo objetivo es mantener separadas la esfera espiritual y social). En este contexto, no existe la clara distinción entre dolencias psicológicas y físicas, propia de la dualidad cuerpo/alma inherente a la epistemología Occidental.

Durante el trabajo de campo se entrevistó a cinco bomohs. Éstos trataban dolencias musculares y fracturas óseas, diagnosticaban patologías mentales (desde el enamoramiento obsesivo a la neurosis), enfermedades graves o posesiones espirituales. Por lo general su tratamiento terapéutico implica el uso de agua y los poderosos versos coránicos recitados a modo de encantos (jampi). El Corán se concibe como una fuente de conocimiento y poder en cuyas páginas se revelan los remedios para todas las dolencias. Junto al Corán, los elementos curativos más comunes responden a elementos hallados en el entorno ecológico circundante: nuez de areca (seri pinang), lima, coco, sal, pimienta, incienso, huevos, etc. El bomob suele dominar las artes de la 
hechicería, los oráculos, la adivinación y el exorcismo —asociado con afecciones psicopatológicas como depresión, esquizofrenia, psicosis, etc.

La diagnosis tiene por objeto detectar e identificar el ibu penyakit (literalmente la "madre de la enfermedad"), el núcleo de la dolencia física o psicológica. Para diagnosticar la enfermedad se emplean oráculos o técnicas adivinatorias y nigrománticas. La nuez de areca, las hojas de tabaco, la sangre del embrión de un huevo ahumado con incienso o la cera de abeja salvaje vertida en un recipiente con agua son, por ejemplo, algunos de los oráculos empleados por los bomohs locales. Para detectar la vía de acceso del mal en el cuerpo, algunos bomob usan masajes (para localizar los puntos vulnerables del cuerpo por los cuales pueden penetrar los espíritus), otros, sus labios, la cuchilla del machete o sus manos impregnadas de incienso y carbón. Otros contactaban con espíritus aliados que les confesaban la enfermedad y el tratamiento, mediante sueños o induciendo el trance. El diagnóstico empieza con la observación de los síntomas, indicios derivados del aspecto de los ojos o la tez, el pulso, la temperatura corporal interior y exterior, signos visibles de enfermedad (hemorragia, mucosidad, decoloración), comportamiento del paciente (locura, relacionado con el exceso calor de la sangre), etc.

Las enfermedades y dolencias más usuales halladas en la isla aparecen en la tabla.

TABLA 1

Patologias detectadas en la sociedad insular (fuente propia: cuestionario)

\begin{tabular}{lrrr}
\hline \multicolumn{1}{c}{ Patología } & Frecuencia & & Porcentaje \\
Ninguna dolencia aparente & 1.260 & & $93,4 \%$ \\
Enfermedad coronaria & 21 & & $1,6 \%$ \\
Deficiencia física & 11 & & $0,8 \%$ \\
Tumores cancerígenos & 8 & & $0,6 \%$ \\
Hipertensión & 8 & & $0,6 \%$ \\
Dolor osteomuscular & 8 & & $0,6 \%$ \\
Asma & 8 & & $0,6 \%$ \\
Afecciones oculares & 5 & & $0,4 \%$ \\
Enfermedades asociadas a la vejez & 4 & & $0,3 \%$ \\
Diabetes & 4 & & $0,3 \%$ \\
Deficiencia mental & 4 & & $0,3 \%$ \\
Cefaleas y altas fiebres & 4 & & $0,3 \%$ \\
Hechicería & 2 & & $0,1 \%$ \\
Apendicitis & 2 & $0,1 \%$ \\
\cline { 1 - 1 } Total & 1.349 & $100 \%$
\end{tabular}


Destacan las enfermedades coronarias (1.6\%) y las minusvalías físicas (0.8\%), seguidas de cáncer, asma, hipertensión, dolores musculares, diabetes, enfermedades mentales y malformaciones congénitas. Al menos en el $20.7 \%$ de las unidades domésticas se ha hallado algún caso de enfermedad de diverso grado y el $6.6 \%$ de la población sufre algún tipo de trastorno crónica. En la isla existe un pequeño ambulatorio y, puesto que la atención sanitaria pública es gratuita, el uso de la biomedicina es mayoritario (98.5\%). Sin embargo, el $33.1 \%$ de los entrevistados asegura hacer uso frecuente de la medicina tradicional.

Por lo general la medicina tradicional no es incompatible con la medicina moderna, pero en ciertos casos pueden surgir desacuerdos que pudieran incidir negativamente sobre el paciente. Por ejemplo, los fármacos modernos se consideran sustancias con cualidades potenciadas (esto es, excesivamente fríos o calientes) y, en ocasiones, el temor de causar un desequilibrio humoral implica el recurso a medicinas tradicionales menos efectivas. En otra ocasión, la sanidad pública promocionó la idea de que tomar duchas en periodo de posparto no entrañaba riesgo para la salud de la mujer y que, en cambio, el tabú alimenticio al que se expone la mujer tras el parto implicaba la carencia de componentes nutricionales importantes. Muchas mujeres siguieron la recomendación médica, pero algunas sufrieron fiebres y, aunque ni la relación con la ducha ni el tabú alimenticio pudo probarse, las mujeres atribuyeron las fiebres a la ruptura del tabú e inculparon a las enfermeras. Otro ejemplo de incompatibilidad remite al consumo de nuez de areca, un ingrediente esencial en la magia malaya cuya ingestión, sin embargo, la OMS relaciona con el cáncer bucal.

En la medicina tradicional — como puede observarse en la tabla- buena parte de las enfermedades se relacionan con la sangre y, en particular, con su contaminación o suciedad (darab kotor). Las hemorragias (derivadas del parto o una circuncisión, por ejemplo) conllevan el enfriamiento del cuerpo e implican periodos de especial vulnerabilidad para la salud. Por esa razón se aplican tabúes consistentes en evitar la ingesta de alimentos fríos (verduras y frutas), se moderan los alimentos calientes (proteínas y grasas) y se consumen preferentemente alimentos neutros (arroz, pescado, etc.).

La dicotomía darab/lendir (sangre/flema) ejemplifica bien la interacción entre humores y enfermedad. Se cree que la sangre se genera directamente a partir de la ingesta de alimentos, particularmente el arroz (Carsten 1997: 110), y es una sustancia connaturalmente caliente y activa. A la inversa, la flema, o lendir, se concibe como una sustancia fría y escasamente dinámica. El lendir tiene la propiedad de coagular en el interior del cuerpo y, en función de la patología, sus efectos pueden ser tanto beneficiosos (por ejemplo en el tratamiento de una fractura ósea) como perjudiciales (cuando 
coagula la sangre y altera su flujo normal). El lendir se halla en alimentos de textura viscosa o gelatinosa, color transparente u opaco y alto contenido acuoso. Sustancias ricas en lendir son la mucosidad, los jugos viscosos, el esperma, la clara del huevo, los frutos gelatinosos, la sustancia segregada de las escamas del pescado o la savia de algunas plantas lechosas. Lendir y darah son elementos opuestos y complementarios en el sistema humoral. El exceso de flema implica obstrucción del riego sanguíneo y enfriamiento de los órganos, ocasionando dolores musculares, adormecimiento de los miembros o parálisis. Para que la sangre adquiera su flujo habitual, el paciente recibe una dieta rica en productos calientes o masajes. Si la sangre es, en cambio, excesivamente caliente, debido a un flujo demasiado rápido o por carencia de lendir, el paciente puede sufrir mareos, vértigos, cefaleas y fatiga. Dolencias como el reumatismo, la impotencia y la infertilidad se relacionan directamente con el flujo sanguíneo. En el pasado, como en la Edad Media europea, se efectuaban purgas de la "sangre impura" (darah kotor) para extraer la enfermedad.

El sistema humoral también explica las características psicológicas del individuo. Por ejemplo, cuando una persona es violenta o agresiva se dice que tiene darah panas ("sangre caliente") y un reinado pacífico se describe como sejuk, "frío"2. Dentro del sistema humoral, el aire (angin) posee un significado general y otro específico. El primero se relaciona con el dolor muscular (producido, se cree, por la acumulación de aire entre los tendones, músculos y órganos) y el segundo con el temperamento individual. En este segundo sentido el angin se describe como un temperamento individual que es heredado y dota a la persona de habilidades, talentos y deseos inherentes según la casuística de una serie de personajes mitológicos. Por ejemplo, en las narraciones mitológicas malayas Angin Dewa Muda es una figura mítica que proclamaba ser el hijo del Rey y la Reina de Java, un Príncipe. Los rasgos de una personalidad heredada de este personaje responden a un individuo que anhela lujos propios de una vida real: ropa de calidad, alimentos exquisitos, vida plácida, amor, respeto y estima por parte de sus conciudadanos. Nacer investido con esa personalidad en un ámbito rural y pobre entraña frustración, pues el individuo no verá sus deseos de lujo aristocrático cubiertos. Otra personalidad arquetípica es la denominada Angin Hala, relacionada con el comportamiento violento y agresivo. De acuerdo con el mito, la madre de esta figura fue accidentalmente fertilizada por un tigre cuando ingirió un fruto en el que el animal había depositado su esper-

\footnotetext{
${ }^{2}$ Nótese que en nuestro vocabulario todavía perviven vestigios humorales en expresiones como "tener sangre fría, "bervir la sangre" o "tener mala leche".
} 
ma. Su hijo, Angin Hala, heredó el temperamento propio de un tigre: agresividad, fortaleza y violencia. Contrariar el temperamento heredado da lugar a una enfermedad denominada sakit berangin (o "enfermedad del aire"), una patología físico-psicológica que agrupa diversas dolencias: lumbago, cefalea, problemas digestivos, asma, depresión, ansiedad e insatisfacción.

\section{ESPÍRITUS Y HECHICERÍA (SYIHIR)}

La creencia en los espíritus está todavía muy extendida en el ámbito rural y no genera incompatibilidades evidentes con el Islam, a pesar de que éste define a las creencias y prácticas animistas como salab ("erróneas"), haram ("prohibidas") o syirik ("no islámicas"). Las narraciones populares respecto a estos temas aludían a espíritus de niños que sollozaban desconsoladamente en las inmediaciones selváticas, encuentros con un tigre, zarandeos súbitos de los hogares, presencia de sombras extrañas, casas abandonadas que emitían sonidos tétricos, accidentes de automóvil causados por espectros o encuentros inesperados con figuras humanas deformes. Con un poco de atención, uno podía detectar indicios de creencias mágicas en las inmediaciones de la aldea: clavos metálicos (por su propiedad fría) incrustados en los árboles para repeler a los espíritus, pinzas de pelo metálicas usadas por mujeres en proceso de posparto para evitar la visita de vampiros, amuletos ocultos bajo la ropa para soslayar la hechicería, o actos rituales antes de entrar en el hogar al anochecer. Algunos informantes afirmaron haber hallado diversos elementos de brujería alrededor de sus hogares: agujas, pelo humano, poliedros con la imagen de Buda, espinas dorsales de puerco ocultas bajo tierra, etc.

En Tuba localizamos un complejo inventario de espectros y fantasmas que coincide con los datos recogidos por otros etnógrafos en diversas zonas malayas (Cf. Winstedt 1951; Endicott 1970). Entre las criaturas fantasmagóricas existen, primero, ancestros protectores con forma animal. Segundo, espíritus libres, ordinarios, de procedencia desconocida. Suelen estar agrupados bajo nombres genéricos (bajang, hantu o momok), habitan en lugares recónditos y son generalmente conjurados para curar o enfermar, realizar sortilegios de amor o ejercer el control sobre otros individuos. En tercer lugar hallamos los demonios de nacimiento, o vampiros, que asumen formas femeninas y se caracterizan por atacar a mujeres parturientas y neonatos. Finalmente, destacan lo que podríamos denominar espíritus familiares, que conforman linajes completos de espíritus. Salvo en el primer caso, los espíritus son malignos y pueden infringir dolor y enfermedad cuando atacan al ser humano. 
Los vampiros son seres antropomorfos, generalmente femeninos, que presentan rasgos inusuales, deformes. Se caracterizan por alimentarse de la sangre de sus víctimas y, en especial, de la sangre sucia o contaminante (darab kotor) de las mujeres que han alumbrado. También pueden atacar a los bebés y a aquellas personas que han sufrido algún accidente o desangramiento -heridos, niños circuncidados, etc. Entre ellos destaca el llamado Pontianak; un diabólico espíritu femenino que se caracteriza por tener la mitad del rostro desfigurada. Según la leyenda popular, este espíritu murió durante el parto y, desde entonces, deambula con el cadáver del hijo en su regazo. Se nutre de la sangre de las mujeres parturientas y de los neonatos, causando enfermedades y la muerte. Otro espíritu popular es Langsuir, un vampiro particularmente temido durante el proceso de gestación, pues se cree que se alimenta de la sangre de las parturientas. Langsuir se describe como una mujer extraordinariamente bella, con una larga y hermosa melena negra y rizada que oculta un orificio en su espalda.

En el ámbito rural, una parte de las enfermedades sigue asociándose a la hechicería (syibir). El fundamento de la hechicería implica un pacto entre conjurador y espíritu con el objetivo de ejercer el control sobre procesos azarosos (productividad, suerte o amor) o sobre una víctima (con fines de venganza, enamoramiento, envidia, etc.). El dominio del espíritu puede realizarse mediante encantamientos, sortilegios y ofrendas. Por lo general, para que el espíritu ataque a una persona se emplearán sus pertenencias o sustancias, cargadas de su semangat, tales como sus cabellos, uñas, una fotografía, ropa o su nombre. La posesión se produce cuando el espíritu proyectado ataca a la víctima y, una vez invade su cuerpo, se resiste a abandonarlo o trata de robarle el semangat (ambil semangat). ¿Cómo se detecta la posesión? Los indicios suelen responder a la etiología propia de la dolencias psicopatológicas (violencia y agresividad, comportamiento compulsivo, comportamiento lascivo, histeria, esquizofrenia...).

Sin embargo, existen ciertas enfermedades halladas en el ámbito malayo que se asocian directamente con la brujería: latab y amok (O'Brien 1883; Kenny 1990). La primera comparte similitudes con la histeria ártica hallada en el caso esquimal. Se percibe como un estado de enajenación temporal provocado por un susto o sobresalto. La víctima, generalmente mujeres de mediana edad, profiere palabras obscenas o imita al que le provoca el sobresalto. Según algunos informantes locales, el latah se produce cuando, a raíz del sobresalto, el semangat abandona temporalmente el cuerpo. La patología denominada $a m o k$, en cambio, se asocia con los varones y se describe como un estado depresivo o psicótico; un episodio de enajenación, agresiva e irreprehensible, cuyo desenlace más posible es, según la leyenda popular, el homicidio masivo. El caso clásico describe a un individuo 
cegado por la ira y armado con un parang (machete local) que avanza inexorablemente por la aldea, asesinando a cuantos individuos encuentra a su paso. El amok indica un caso de posesión. Para tratar la posesión se requiere un exorcismo por el cual el bomoh, que entra en contacto con las fuerzas espirituales, obliga al espíritu a abandonar el cuerpo de la víctima, dado que su función es reequilibrar el universo y evitar que se mezclen los espíritus con los humanos. Este contacto puede realizarse mediante sueños o trance.

\section{ALMA Y BRUJERÍA}

A lo largo del artículo hemos hecho referencia al alma o semangat, un elemento que implica también elementos sincréticos propios del Islam y el animismo. De acuerdo con el profesor de religión local (ustaz), Alá creó el mundo usando los cuatro elementos humorales y luego creó al ser humano con tierra. Alá ofreció el aliento al arcángel Gabriel para que lo insuflase en el cuerpo de Adán, compuesto sólo de tierra y agua. Gabriel, involuntariamente, abrió su puño y dejó escapar una parte del aliento que, al no hallar recipiente corporal en el que introducirse, devino un hantu, un espíritu, o el hermano incorpóreo de Adán. Desde su nacimiento accidental, la relación con su hermano humano ha sido ambivalente: se muestra temeroso ante la superioridad del humano, pero también rencoroso, pues el espíritu fue relegado perpetuamente a la oscuridad, al contrario que su hermano humano.

Los espíritus se describen simultáneamente como unitarios y múltiples, posiblemente debido al influjo sincrético del antiguo panteísmo sufí. El espíritu se conceptualiza como aire (angin) extraordinariamente caliente, pues es expeliendo su aliento sobre el cuerpo humano como causa el desequilibrio humoral y la dolencia. Esta interpretación es congruente con ideas originales del Islam medieval, que concebían la fiebre como una exhalación del Infierno (Brown 1921, en Endicott 1970). Panas (caliente) es la antítesis de lo sagrado (frí) y por esta razón la brujería recibe el nombre de ilmu panas (conocimiento caliente) y los chamanes aplican remedios fríos mediante baños, agua, el soplo de su aliento o los versos coránicos, con el objetivo de repeler a los espíritus causantes del mal físico o psicológico.

Según los malayos, el alma está integrada por tres elementos: semangat, nyawa y rub. El semangat se traduce generalmente como espiritu de la vida y es una fuerza vital presente en casi todos los objetos animados o inanimados: en las distintas partes del cuerpo humano (placenta, pelo, uñas...), en su sombra, en el agua donde se baña, en plantas y animales, montañas, hierro, mar, jungla, arroz e incluso en el bote o el hogar. Este elemento presenta muchas semejanzas con el alma o espiritu en el sentido ancestral 
indonesio o con el mana melanesio (Winstedt 1951: 19). En el ser humano, el semangat es como "la puerta del cuerpo que protege la casa contra los intrusos" (Kenny 1990: 129; Laderman 1983: 20). Los habitantes locales decían que ( sic) semangat jadi sendiri; es decir, "el semangat surge solo". En el ser humano, el semangat surge cuando se extirpa el cordón umbilical y en el objeto, por ejemplo en el hogar o en el bote, una vez finalizada su construcción. El semangat es, por lo tanto, una fuerza animista inmanente al propio objeto o sujeto, que sólo cobra existencia cuando se ha consumado el proceso de devenir (jadi).

En el momento del nacimiento, tanto animales como seres humanos inhalan el nyawa, o nadi, traducido como aliento de la vida, que contiene los cuatro elementos humorales. El nyawa se concibe como el pulso vital o energía y se describe como un aliento o soplo. De acuerdo con los aldeanos, el nadi surge del cerebro y desciende al estómago antes de engendrar. Entra en el cuerpo del bebé a partir del sexto mes y le dota de vitalidad. De hecho, cuando el animal o el humano fallecen en condiciones normales, su nyawa abandona el cuerpo y el aliento o la vitalidad se extinguen. Pero si el animal o el ser humano mueren en condiciones extrañas, súbitas o violentas (por ejemplo asesinados), su nyawa se transforma en otra sustancia contaminante y muy caliente denominada badi.

Por último el rub responde a un componente exclusivo del alma humana; es la sustancia que transmigra al cielo o al infierno, el alma según se concibe en las tradiciones religiosas abrahámicas.

\section{LA REPRODUCCIÓN Y EL PARTO}

El nexo entre humores, animismo e Islam se manifiesta particularmente en ciertos ritos de paso, procesos relevantes para el individuo y la sociedad generalmente vinculados a cambios de estatus social o desarrollos biológicos.

La concepción tradicional de la procreación considera que el ser humano se origina a partir de la semilla masculina (esperma) formada en el cerebro del progenitor, donde recibe la racionalidad (akal), característica que distingue al ser humano de los espíritus, los ángeles y los animales. Desde el cerebro, la semilla desciende al pecho, considerado el centro microcósmico del universo, para alojarse luego en el hígado (hati) donde adquiere las emociones, sentimientos y afectos, si bien será la madre la que fijará las características psicológicas y emocionales del bebé. Luego la semilla desciende por la espina dorsal del hombre hasta el pene y se introduce en la mujer, donde asume los cuatro elementos humorales a través de su sangre: agua, fuego, tierra y aire. 
Los ritos de paso femeninos más decisivos y significativos acontecen durante el parto y el posparto, mientras que durante el periodo de embarazo la mujer suele realizar las tareas cotidianas sin atenciones particulares. Los tabúes, en cambio, recaen sobre el genitor. El marido debe abstenerse de maltratar animales (golpear al ganado, herir a serpientes marinas o, durante la pesca, causar daño innecesario a peces o cangrejos). En caso contrario se cree que se incrementa el riesgo de deficiencia física en el feto. Así, por el ejemplo, si el marido fractura la pinza de un cangrejo se cree que el neonato podría nacer manco o con otro tipo de malformaciones en sus extremidades. De igual modo, los abundantes casos de labio leporino se achacan a que el marido desgarró la boca de un pez que escapó al extraerle el anzuelo. Este riesgo no se produce cuando se sacrifica un animal con fines alimenticios. Los malayos consideran que el feto adquiere propiedades humanas sólo a partir del cuarto mes. Con anterioridad el feto se concibe como un coágulo de sangre. Al sexto mes recibe el nyawa, o "aliento de la vida", y deviene persona. A partir de ese momento, su madre debe estar particularmente alerta ante situaciones que pudieran provocar la huida temporal del semangat: sobresaltos, hechicería, fuertes emociones, etc.

En un pasado no muy lejano, la mujer parturienta era atendida por una partera tradicional (bidan) que seguía el proceso de embarazo o detectaba posibles problemas y afecciones del recién nacido mediante masajes y palpando el útero. Al séptimo mes de embarazo tenía lugar el ritual denominado mandi perut ("baño del vientre") de la embarazada, consistente en masajear su vientre con un coco (seleccionado por su perfección en la forma) y huevos de gallina. Tras el masaje, el coco y los huevos se arrojaban al suelo y, si no se rompían, se auguraban malas consecuencias para el feto. Al anochecer, la mujer embarazada debía salir al exterior y dar tres vueltas caminando alrededor de su hogar. Finalmente, el marido y la esposa recibían un baño ritual a cargo de la bidan. Situados bajo la escalera del hogar eran rociados por aquélla con cubos repletos de agua, flores de arroz y maderas aromáticas. La mujer vestía el sarong (prenda típica malaya e indonesia parecida a una falda) del marido y ambos pedían un deseo relacionado con la buenaventura del futuro hijo.

Tras el nacimiento se espera que el bebé llore. De lo contrario la bidan dará masaje a la placenta para que aquélla transfiera el semangat al neonato. En efecto, la placenta (uri) posee en la sociedad malaya un significado especial, se cree que bayi dan uri sama, macam adik-beradik ("la placenta y el neonato son lo mismo, son como hermanos"). Tras el nacimiento, la placenta se limpia y se envuelve en un paño blanco, al que también se le añade sal (garam), un clavo metálico (paku), pimienta (lada), plantas aromáticas (kunyit), tamarindo y fruta ácida. Todos estos elementos poseen un 
significado simbólico y, en ciertos casos, funcional: el metal (elemento frío) repele los malos espíritus y el tamarindo y la sal desecan la placenta. El padre excavará un agujero debajo del hogar y enterrará el paño con su contenido. Una aldeana me explicó que si el bebé era varón su placenta debía enterrarse detrás de la casa (para retrasar el abandono del hogar del hijo), pero si era mujer debía hacerse delante (para acelerar su matrimonio). Este rito ilustra por lo tanto la dependencia entre padres e hijos y, posiblemente, la predilección musulmana por el primogénito varón (Djamour 1959; Carsten 1997; Banks 1983). El agujero se cubrirá de tierra y en la superficie se encenderá una hoguera que se mantendrá avivada durante una semana, para espantar, tanto a espíritus malignos, como a posibles animales carroñeros.

Tras el parto, al bebé varón se le recitará al oído derecho y de modo vigoroso, el azan o las primeras frases del llamamiento al rezo. Si es niña se le susurrará al oído izquierdo, de modo pausado y dulce, el kamat, por el cual se insta a los fieles musulmanes a levantarse y rezar. Se le cortará el cordón umbilical usando un cuchillo de bambú, y no de metal, para no espantar al semangat, o alma, del recién nacido.

En el caso de la madre, el periodo de posparto está sujeto a un estricto tabú alimenticio (pantang) durante 44 días. En el pasado, durante este tiempo la mujer debía permanecer prácticamente inmóvil en el gerai, plataforma de madera que se construía en el interior del hogar y bajo la cual se encendía una lumbre para mantener su cuerpo caliente. Tras la cuarentena el niño era ceremonialmente presentado a los espíritus animistas (la Madre Tierra y el Padre Agua). Aunque estos rituales ya no se realizan, el parto es un momento de especial atención simbólica, pues el cuerpo de la mujer, debilitado por la pérdida de sangre, atrae a los espíritus malignos y vampiros. Para evitar el ataque, la mujer evitará salir al exterior del hogar y se recogerá el pelo utilizando un clavo metálico para repeler a los espíritus.

Durante el pantang la mujer debe abstenerse de tener contacto con elementos fríos: evitar ducharse con agua fría, beber en exceso o comer alimentos fríos para mejorar su estado de salud. Durante las primeras semanas de este periodo, su dieta se reduce a arroz, pescado a la plancha, pollo y curry. El tabú es especialmente rígido con los alimentos bisa (marisco y algunas especies marinas concretas) y se sigue de otras prescripciones particulares: evitar movimientos bruscos, no exponerse a malos olores (asociados con la presencia espectral) y evitar sobre todo las hemorragias. Tras el parto se cree que el interior de su cuerpo (sus músculos, entrañas) ha sufrido un desorden importante y ha acumulado aire (angin). Para restituir el estado normal, la mujer masajeará, dos o tres veces al día, su vientre con el tungku: una piedra caliente y envuelta en un paño. Con este tratamiento se evita el gila meroyan, una enfermedad que se describe como un tipo de 
enajenación transitoria, provocada por un flujo sanguíneo insuficiente. De acuerdo con una informante, este tipo de locura se genera "cuando la sangre del útero llega al cerebro". Según ésta:

tras el parto los músculos del vientre (o del útero) de la mujer se dilatan [e imbrican], formando un amasijo de músculos y carne endurecida que produce un intenso dolor muscular (sakit urat) [...] La función del tungku es secar el interior del vientre [pues tras el parto se considera que el útero desprende sangre que se filtra a otros órganos] y distender los músculos para liberar el angin (aire) acumulado entre los órganos.

Otras enfermedades comunes en el periodo de posparto son, según las entrevistadas, las denominadas localmente gila meyoran ("locura"), kudis meyoran (enfermedades cutáneas), kancing gigi (posiblemente epilepsia), demam (fiebres), lorah (depresión), bisa darah (envenenamiento de la sangre), badan keras (rigidez corporal), turun darab (hemorragia) o angin darah (literalmente "aire en la sangre"), descrito como aire que bloquea la circulación sanguínea.

\section{NACIMIENTO E INFANCIA}

Se cree que el niño nace frío y en estado de conmoción, razón por la cual, a pesar de las altas temperaturas tropicales, tras su nacimiento su torso se ciñe con un paño tan ajustado que apenas le permite mover las extremidades; su cabeza se cubre con un gorro, sus manos con guantes y sus pies con patucos (Cf. Gorer y Rickman 1950). La reproducción no se considera exitosa ni plena hasta que no se desprende el cordón umbilical, simbolizando la separación física y simbólica entre madre e hijo. En este rito la bidan rapa la cabeza del bebé en honor al profeta Mohammed, recibiendo a cambio obsequios (arroz, miel, huevos, carne de coco y nueces de areca).

El Islam recomienda amamantar a la criatura por más de veinte meses $y$, en efecto, en Tuba el periodo de lactancia es dilatado, pero por otras razones: se cree que la leche de la madre imprime al neonato sus particulares características psicológicas. Amamantar, por lo tanto, significa fortalecer los vínculos emocionales y prevenir posibles enfermedades psicológicas (Carsten 1997: 109).

Durante la primera infancia son mecidos en un sarong suspendido del techo mediante muelles metálicos. Esta singular mecedora es también la protagonista de un importante rito de paso denominado berandui, que tiene lugar sólo tras el nacimiento del primogénito. La etimología del nombre del ritual remite, tanto a la cuna tradicional malaya (berayandui), como a 
las nanas musulmanas (bersanji). Durante el ritual, la cuna suspendida del techo se adorna con elementos propios de la tradición hindú (flores, incienso, plátanos y arroz tostado) y se insertan dos anillos matrimoniales (de los padres) y una cadena de oro (de la abuela materna). El niño se coloca en la cuna adornada mientras llegan los parientes y vecinos. Los varones se aposentarán en la sala principal para orar y las mujeres lo harán segregadas, en la cocina. El infante, dispuesto en la cuna ornamental, será mecido por su padre mientras algunos hombres le dedican bedikel, especie de saetas como (sic) Oh, besar anak ku jadi orang berguna! (“'Oh!, ¡Niño crece y conviértete en una persona de bien!”). La ceremonia, como es común, finaliza con un acto de comensalidad (denominado kenduri).

En el pasado estos ritos eran más ceremoniosos y se impregnaban de influencias animistas. Por ejemplo, el especialista ritual pasaba la cadena y los anillos por sus labios para conferirles poder y limpieza, y los padres colgaban el berandui de un cocotero y lo mecían. También en el pasado, los cordones umbilicales secos de los sucesivos hijos se guardaban en un frasco con agua. Agotado el periodo reproductivo de la madre, el líquido era ingerido por los parientes en un acto ceremonial. El fin de esta práctica era evitar los posibles conflictos futuros entre los hermanos y, por lo general, todos estos ritos perseguían asegurar la buenaventura de los hijos. La desaparición de esos ritos se debe en buena parte al efecto de la creciente ortodoxia musulmana.

\section{CIRCUNCISIÓN}

El Islam prescribe la circuncisión, bersunat, por cuestiones higiénicas y simbólicas: porque se cree que el cuerpo del individuo será más limpio y porque se considera un mandato de Alá. La circuncisión significa el acto ritual por el cual el malayo masuk Islam (literalmente "entra" o "deviene musulmán"). En el pasado la realizaban ancianos especialistas que utilizaban para la operación un cuchillo de bambú (pisau sunat). Hoy en día la mayoría se circuncida en el hospital local.

En el caso masculino la circuncisión se produce entre los siete y doce años, cuando el niño ha recibido la instrucción islámica básica y ha leído por completo el Corán. En el caso femenino, la mutilación genital (ablación del clítoris) se produce entre las primeras semanas y los cuatro meses, ya que (sic) kalau perempuan faham tak boleh, sebab dia sudab pandai, dan jadi malu dan jahat ("si la niña comprende ya no se puede, pues es consciente y se vuelve vergonzosa, traviesa"). Tras esta afirmación subyacen las ideas musulmanas respecto a los humores y la segregación sexual: aunque 
la circuncisión femenina no es obligatoria, y es en la práctica rara, se considera (o al menos así opinaba el maestro de religión local) que en caso de no ser circuncidada la mujer no lograría nunca quedar sexualmente satisfecha y esto entrañaba el riesgo de la promiscuidad. Mientras que la circuncisión femenina no implica ningún ceremonial específico, el niño circuncidado será nuevamente rapado para protagonizar un festín en el que se le ofrecen regalos, mientras yace postrado en una hamaca o colchón durante una o dos semanas. Éste seguirá el mismo tabú (pantang) que acata la mujer durante el periodo de posparto. El tabú alimenticio parece marcar así dos ritos de género fundamentales relacionados con la iniciación al proceso reproductivo. El varón, a partir de la circuncisión, gozará de un mayor estatus, del mismo modo que ocurre con la mujer que ha dado por primera vez a luz.

\section{MUERTE}

El cuerpo del difunto debe enterrarse inmediatamente después de lavarlo y vaciar su estómago (baruang). El vaciado del estómago lo llevan a cabo unas especialistas que reciben una pequeña suma económica o, en ocasiones, algún objeto de valor del fallecido (una sortija, por ejemplo). La limpieza del estómago se relaciona con la noción ritual de limpieza y con el mito del eterno retorno. De acuerdo con los lugareños, a la tierra llegamos con el estómago vacío y, por lo tanto, la partida de este mundo debe realizarse del mismo modo: dalam perut tak boleb ada makanan ("dentro del estómago no puede haber comida”). Tras lavar y vaciar el cuerpo mediante la aplicación de masajes, se taponan todos sus orificios y se aplica algodón en sus articulaciones (rodillas, codos, etc.) y en el rostro. El cuerpo se amortaja con un paño blanco de algodón impregnado de plantas aromáticas y perfumes naturales - flores, especias y lima. Finalmente, dispuesto sobre una tarima de madera, se cubre con la alfombra del rezo y se transporta a hombros por un grupo de varones (parientes, vecinos y acompañantes) hasta la mezquita. Durante esta procesión, uno de los varones cubrirá el cuerpo con una sombrilla, mientras la comitiva femenina seguirá al grupo masculino a cierta distancia. En la mezquita el imam liderará un rezo comunitario dedicado al difunto antes de dar sepultura al cuerpo, que se coloca del costado derecho y en dirección a la Meca.

La misma tarde del entierro, la familia del difunto abrirá sus puertas para recibir las visitas de la mayoría de los miembros de la aldea, a los que se les ofrecerán dulces, té y café. Las mujeres, con sus niños, permanecerán en el exterior, donde cocinarán más alimentos para la velada, mientras que los hombres rezarán en el interior. Los asistentes regresarán luego a sus ho- 
gares respectivos para tomar una ducha, pues existe la creencia de que la "sangre" del difunto podría contaminarles o transmitirles la dolencia. Cuando el individuo fallece se cree que su cuerpo se seca y se vacía de sangre, volviéndose frío. Sin embargo, darah itu tak boleh nampak ("esta sangre no se puede ver") y se interpreta, de acuerdo con los informantes, como el último suspiro del difunto, un aliento contaminante que podría ocasionar la enfermedad. Esta interpretación encaja con la creencia en el badi y el nyawa.

Tras el fallecimiento, durante el primer día, el $3^{\circ}$, el $7^{\circ}$, el $44^{\circ}$, el $100^{\circ}$ y, finalmente, al cabo de un año, el rub del fallecido, guiado por un ángel, visitará su hogar y a sus parientes para despedirse progresivamente, antes de formar parte de la grandeza de Alá. Con motivo de cada visita del alma del fallecido, su familia realizará un kenduri (acto de comensalía) en memoria del difunto. De hecho, el kenduri es un ceremonial que acompaña a todos los ritos aquí expuestos. Compartir alimento es, para la sociedad malaya, un acto fundamental de cohesión social.

\section{CONCLUSIONES}

Como hemos mostrado, los ceremoniales malayos ofrecen una rica manifestación sincrética, producto de diversas influencias: hinduismo, Islam, animismo, chamanismo, etc. (Valenzuela 2006a). Estos principios se hacen particularmente manifiestos en los ritos de paso. Cuando se salva el sincretismo que impregna estos rituales (que dotan por supuesto de singularidad cultural a la sociedad malaya) se revela un sustrato islámico que articula y permite entender otros tantos aspectos sociales de la sociedad malaya y, por extensión, de otras sociedades musulmanas. Por lo tanto, más allá del coleccionismo etnográfico, o del placer humanista por explorar y conocer otros modos de vida, el estudio de los ritos de paso pudiera tener un valor añadido, pragmático.

A partir de los rasgos que caracterizan esos ritos puede derivarse un modelo que ofrece pistas relevantes sobre la comprensión de la persona, la salud y la enfermedad. Este modelo permite realizar un doble ejercicio, comparativo y aplicado. Por una parte, a partir del caso malayo (salvando las singularidades culturales específicas) podría establecerse una comparación etnográfica con otras poblaciones asiáticas y musulmanas respecto a la comprensión de la persona, la salud y la enfermedad. Este sería el caso, por ejemplo, de comunidades escasamente analizadas por la etnografía nacional, como poblaciones pakistaníes, bangladeshíes o indias, cuya cultura sincretiza elementos derivados de religiones universales (hinduismo, Islam) con vestigios animistas regionales (Valenzuela 2009). 
Por otra parte, el modelo permite destilar un conocimiento aplicado al ámbito de la atención sanitaria en el contexto de la biomedicina contemporánea. Los modelos etnográficos, hasta la fecha, no habían sido particularmente útiles en contextos socioculturales más o menos homogéneos. Sin embargo, los grandes flujos migratorios de esta década están cambiando el contexto y las prioridades. Actualmente, el 17,6\% de los inmigrantes que llegan a España procede de África y el $5 \%$ de Asia, los continentes con mayor población musulmana del mundo (Baldwin-Edwards 2007). En este escenario, la comparación etnográfica posee un valor esencial como fuente de información para construir puentes de comprensión intercultural al servicio de la asistencia médica. Es en este marco, precisamente, en el que surgen nuevas y vigorosas oportunidades para una antropología de la salud aplicada y renovada, que coaligue el saber etnográfico clásico con las nuevas necesidades sociales contemporáneas ${ }^{3}$.

\section{BIBLIOGRAFÍA CITADA}

Abraham, C. E. R. 2004. The Naked Social Order. The Roots of Racial Polarisation in Malaysia. Kuala Lumpur: Pelanduk Publications.

Ahmat, S. 1980. Tradition and Change in a Malay State: A Study of the Economic and Political Development of Kedah 1878-1923. Singapur: The Malaysian Branch of the Royal Asiatic Society, Monografía n. 12 .

Andaya, B. W. y Andaya, L. Y. 1982. A History of Malaysia. Londres: McMillan.

Bailey, C. 1983. The Sociology of Production in Rural Malay Society. East Asia Social Science Monograph. Oxford: Oxford University Press.

Baldwin-Edwards, M. 2007. "La migración en la región del Mediterráneo". Vanguardia Dossier 22.

Banks, D. J. 1983. Malay Kinship. Filadelfia: Institute for the Study of Human Issues.

Carsten, J. 1997. The Heat of the Hearth. The Process of Kinship in a Malay Fishing Community. Oxford: Oxford University Press.

Dentan, R. K. et al. 1997. Malaysia and the Original People. A Case Study of the Impact of Development on Indigenous Peoples. Cultural Survival Studies in Ethnicity and Change. Boston: Allyn and Bacon.

Djamour, J. 1959. Malay Kinship and Marriage in Singapore. London School of Economics. Monographs on Social Anthropology n. ${ }^{\circ}$ 21. Londres: The Athlone Press.

Endicott, K. M. 1970. An Analysis of Malay Magic. Oxford: Clarendon Press.

Geertz, C. 1971. Islam Observed: Religious Development in Morocco and Indonesia. Chicago: University of Chicago Press.

Good B. M. y Del Vecchio J. 1992. "The comparative Study of Greco-Islamic Medicine: The Integration of Medical Knowledge into Local Symbolic Contexts", en Leslie, Charles

\footnotetext{
${ }^{3}$ Este artículo es fruto de la investigación financiada por la DGICYT, "Teoría transcultural de la reproducción de los grupos humanos. Los modelos socioculturales de procreación y crianza de niños". SEJ2006-10864/SOCI. IP, Aurora González Echevarría.
} 
y Allan Young (eds.), Paths to Asian Medical Knowledge. Berkeley: University of California Press.

Gorer, G. y Rickma, J. 1950. The People of Great Russia: A Psychological Study. Nueva York: Chanticleer.

Kenny, M. G. 1990. "Latah: The Logic of Fear", en Karim, W. J. (ed.), Emotions of Culture. A Malay Perspective. Singapur: Oxford University Press.

Laderman, C. 1983. Wives and Midwives. Childbirth and Nutrition in Rural Malaysia. The Regents of the University of California. Berkeley: University of California Press.

Laderman, C. 1991. Taming the Wind of Desire. Psychology, Medicine, and Aesthetics in Malay Shamanistic Performance. Berkeley: University of California Press.

Nagata, J. 1974. "What is a Malay: Situational Selection of Ethnic Identity in a Plural Society". Man LXI (219): 189-91.

Nagata, J. 1976. "Kinship and Social Mobility among the Malays". Man (n.s.) 11: 400409.

Nagata, J. 1984. The Reflowering of Malaysian Islam. Modern Religious Radical and their Roots. Vancouver: University of British Columbia Press.

Nicholas, C. 2000. The Orang Asli and the Contest for Resources. Indigenous Politics, Development and Identity in Peninsular Malaysia. Iwgia Document ํㅡ. 95. Copenhage: International Work Group for Indigenous Affairs.

O'Brien, H. A. 1883. "Latah". Journal of the Malayan Branch of the Royal Asian Society 11: $143-155$.

Omar Farouk. 1998. "The Dynamics of Islamization, Arabisation and Localisation in the Malay World". Malay Studies Working Papers, n.. 1 . Nueva Zelanda: Victoria University of Wellington.

Osborne, M. 2000. Southeast Asia. An Introductory History. Australia: Allen and Unwin, 8 th edition.

Said, K. M. 1993. The Despairing and the Hopeful. A Malay Fishing Community in Kuala Kedah. Bangui, Selangor, Malaysia: Penerbitan University Kebangsaan Malaysia.

Valenzuela García, H. 2006a. "Sistemes de valors i fet religiós en les societats del sudest asiàtic. Sincretisme i diversitat". Revista DCIDOB 99: Pensament i religió a l'Àsia. Barcelona: Ediciones Bellaterra.

Valenzuela García, H. 2006b. La Isla de las Víctimas de la Complicidad: Economía, politica, dialéctica y cultura de los pescadores de Pulau Tuba, Langkawi, Estado de Kedah, Malaysia. Tesis doctoral. Universidad Autónoma de Barcelona.

Valenzuela García, H. 2009. "Transmigración y Salud. Acceso y uso del sistema sanitario entre el colectivo pakistaní de Barcelona", en VV.AA (eds.), Transnacionalismo y Salud. México: UAM (en prensa).

Winsted, R. 1951. The Malay Magician Being Shaman, Saiva and Sufi. Londres: Routledge.

Fecha de recepción: 19 de agosto de 2008

Fecha de aceptación: 20 de mayo de 2009 